\title{
Principios que rigen la actuación del abogado como auxiliar de la justicia en la prevención de la corrupción
}

\author{
Principles that govern the actions of the lawyer \\ as an auxiliary of justice in in corruption prevention
}

\author{
Alizia Agnelli Faggioli \\ Doctora en Ciencias de la Educación \\ Postdoctora en Estudios Postdoctorales \\ Docente titular e investigadora de la Universidad Metropolitana de Ecuador \\ aliziagnelli@gmail.com
}

\begin{abstract}
Marily Rafaela Fuentes Águila
Doctora en Ciencias Jurídicas

Docente titular e investigadora de la Universidad Metropolitana de Ecuador fuentesmarily6811@gmail.com
\end{abstract}

\author{
Pedro Enrique Castellanos Fuentes \\ Magíster en Ciencias Jurídicas \\ Universidad Metropolitana de Ecuador \\ p.e.castelf@gmail.com
}




\section{Resumen}

El presente artículo aborda el tema acerca de los principios rectores de actuación del abogado como auxiliar de la justicia, en cuyo oficio debe tener como guía en su desempeño la ética, la lealtad, la honestidad y la responsabilidad, valores que contribuyen a evitar y combatir el flagelo de la corrupción a través de la ley como único mecanismo ante los órganos judiciales, en la búsqueda de una verdadera justicia, la cual, a pesar de que es labor del juez, ve en el abogado su correcta presentación. La metodología utilizada fue de tipo documental, con un nivel descriptivo, considerando que se trata de sustentar el estudio con información disponible en las fuentes formales escritas de las ciencias jurídicas. Se concluye que el abogado debe coadyuvar en la lucha contra la corrupción en compromiso conjunto con los jueces y demás empleados judiciales, lo que es fundamental para dignificar la profesión como un aporte en el camino hacia un verdadero Estado social de Derecho.

\section{Palabras clave}

Abogado; principios; prevención; corrupción; justicia.

\section{Abstract}

The present article addresses the subject of the guiding principles of action of the lawyer as an auxiliary of justice, in whose profession he must have ethics, loyalty, honesty, and responsibility as his duty guide; values that contribute to avoid and battle the corruption scourge through the law as the only mechanism before judicial bodies in the search for true justice which, despite being the judge's duty, sees the correct presentation of the lawyer. The methodology used was of a documentary type, with a descriptive level considering it is about supporting the study with the available information of written formal sources of legal sciences.

It is concluded that the lawyer must contribute to fight corruption in a commitment along with judges and other court employees, which is fundamental to dignify the profession as a contribution in the path to a real Social Rule of Law

\section{Keywords}

lawyer, principles, prevention, corruption, justice.

\footnotetext{
Cómo citar este artículo:

Agnelli, F., Fuentes, M., y Castellanos, P. (2021). Principios que rigen la actuación del abogado como auxiliar de la justicia en la prevención de la corrupción judicial. Revista de la Facultad de Derecho y Ciencias Políticas, 51(135), pp. 348 - 367. doi: https://doi.org/10.18566/rfdcp.v51n135.a03
}

Recibido: 21 de octubre de 2019

Aprobado: 19 de octubre de 2020 


\section{Introducción}

Cuando se menciona el vocablo abogado, se espera el reflejo de una persona con una conducta ética, que se identifica dentro del ámbito jurídico con un proceder correcto, que cumple con lo plasmado en los códigos éticos del profesional en derecho y que debe regirse por los parámetros de la deontología. Lastimosamente no siempre esa es la imagen que se tiene de este profesional de las leyes, pues muchas personas lo perciben como un sujeto que, lejos de dar solución a sus problemas, comienza a crear otros, desde el primer momento en que interactúa con el cliente.

Quien quiera dedicarse a la abogacía debe, desde los propios inicios de la carrera de derecho, ir cultivando las bases positivas del futuro profesional en que ha de convertirse. El respeto, la transparencia, la pasión por los problemas de la otra persona tienen que constituirse en base ética en su formación universitaria.

Sin firmeza de carácter para no transigir con lo malo, sin principios de honradez que arraiguen profundamente en su espíritu, jamás puede el abogado alzarse a mayor altura en la sincera estimación de sus conciudadanos, aunque le adornen, por otra parte, notables dotes de ingenio y de saber. La elocuencia misma, con su poderoso atractivo, no llega a producir efectos de importancia en las líneas forenses, cuando falla al orador autoridad moral. Es como el sol de invierno en las regiones frías: brilla, pero no calienta. (Córdova, 1913, p. 4)

El abogado viene a ser un auxiliar de la justicia, por ello, su principal función es contribuir a impartirla, por lo que su labor debe ser la búsqueda de la verdad, luchando para que ella triunfe y, de esa manera, pueda consolidarse y respetarse el Estado de Derecho. Aunque parezca paradójico, muchos abogados no están conscientes de la necesidad de ser honestos y modestos colaboradores de la justicia.

La abogacía es para la justicia. Desde fuera, los que no nos comprenden, se sonreirán malignos. Desde dentro, los que no nos aman, porque también entre los abogados hay, aunque excepcionalmente, quienes no tienen ni amor ni respeto por su profesión, se encontrarán por lo menos confundidos. El abogado no sirve al cliente, sino a la justicia, en interés o en la defensa del cliente. Por eso debe tener sentido o instinto de lo justo. Es más: quien lo tenga en grado eminente no podrá ser otra cosa que abogado. (Viñas, 1972 , p. 139) 
La profesión de la abogacía se fundamenta en la deontología jurídica, que conforma el conjunto de reglas y principios que rigen determinadas conductas del profesional, y remiten directamente al deber ser de cada profesión, a normas y valores del quehacer laboral que tiene significado en la medida en que son dirigidas al ser (Lega, 1983, p. 287). Tanto los jueces, los fiscales, notarios, y demás juristas, como el abogado, tienen el deber de comportarse éticamente.

Aunque es cierto que entre los juristas se debaten distintas tesis sobre los intereses que deben defender los abogados, y se reconoce el compromiso del abogado con su cliente, este no debe olvidar sus valores y compromiso consigo mismo, con su profesión y con la sociedad (Ochoa, 2015). En su obra, al debatir sobre qué intereses deben defenderse, Ochoa hacía referencia a un aspecto muy importante y es la necesidad de analizar el caso concreto en que el abogado se sitúa en el punto crítico en que quizás los intereses de su cliente no sean los que debe defender.

Si bien la regla es que el abogado se debe al cliente, y teniendo en cuenta que entre ellos dos se concibió un pacto, un contrato que impone al abogado una actuación conforme a las pretensiones de aquel, cuando el interés del cliente puede causar un grave perjuicio que se conoce injusto, 0 cuando pueda afectar al propio abogado o a la sociedad, con actitudes mezquinas, injustas, ilegítimas, fraudulentas que impliquen un riesgo contra un tercero, no debe el abogado provocar la injusticia de un fallo notablemente injusto y contrario a derecho (Monroy-Cabra, 2005). Este autor, refiriéndose al abogado, decía que

(...) no se puede cooperar para el mal ni puede existir complicidad en las pruebas dolosas o medios inmorales o ilícitos. La única manera de eliminar lo que huele a podrido es aumentar la calidad de las actuaciones deontológicas claras y morales. (Monroy-Cabra, 2006, p. 25).

El artículo 83, en el numeral 12 de la Constitución Política de la República del Ecuador, exige a los ecuatorianos ejercer la profesión u oficio con sujeción a la ética, y ello implica que el profesional que ejerce la abogacía deba asumir sus funciones ajustándose a estas reglas, que son comunes para cualquier persona que se haya formado para cumplir una función dentro de la sociedad. Sobre todo, del profesional del derecho debía esperarse una actitud correcta y un comportamiento ético (Asamblea Nacional , 2008).

Aunque todavía hay quienes consideran que la abogacía es un servicio exclusivamente privado, y que, ciertamente, en sus inicios nació para ofrecer 
apoyo a intereses particulares, a partir del momento en que la justicia pasó a ser una prestación para la colectividad, para la sociedad en general, cuando quedó establecido que la justicia es para todos, por supuesto que el rol del abogado deja de ser aquel exclusivamente individual para transformarse en un ente que actúa para el bien común.

Con independencia de su deber y compromiso con el cliente, el abogado asume responsabilidades para con los demás integrantes de la sociedad y, una de ellas es la lucha contra un grave flagelo, la corrupción, sobre todo aquella que está más cerca de él, que es la corrupción judicial. Esta tiene una raíz en la injusticia, que trae como consecuencia costos judiciales, económicos y políticos, y que pone en juicio la credibilidad de los encargados de administrar justicia.

La corrupción judicial es un fenómeno que viene manifestándose de manera trascendental en los países de la región latinoamericana. Las informaciones mayormente diseminadas en la ciudadanía están vinculadas a la actuación de jueces en el ejercicio de sus funciones, además de los empleados judiciales, que se dedican a la petición o exigencias de regalos o dineros, generalmente a través de los abogados, quienes, a su vez, les reclaman a sus clientes para conseguir, como mínimo, agilizar el proceso.

Actos que aparentan ser insignificantes en los órganos judiciales pueden traer aparejados hechos primarios de corrupción, como pudiera ser la demora en los trámites procesales. La dilación injustificada por parte de los jueces o secretarios judiciales, e incluso el retardo de los abogados en la presentación de un escrito, puede provocar desde el propio inicio del proceso un acto de corrupción.

Para que en el sistema judicial se evite la corrupción, en primer e ineludible lugar, debe ser él mismo un ejemplo de limpieza y honestidad. En segundo lugar, juzgar los hechos de corrupción como corresponde con su gravedad, y en el tercero, contar con abogados que actúen de conformidad con las normas que imponen el respeto por la transparencia e imparcialidad de la justicia (Liscano, 1973, p. 43).

Según informes internacionales, dentro de los problemas que se presentan hoy en los sistemas judiciales de la región se encuentra el de los “abogados corruptores”. Para la población, los abogados más prestigiosos son, lógicamente, quienes ganan los casos, pero muchas veces ello se consigue con una buena red de relaciones y un abundante flujo de dinero, que acaba, en gran 
parte, en manos de los jueces corruptos. La capacidad y los conocimientos jurídicos del buen abogado no bastan e incluso, son redundantes (Escobar Luque, 2013, p.111).

En virtud de lo anterior, el abogado juega un papel importante y esencial en la prevención de la corrupción judicial como auxiliar de la justicia, es lo que la sociedad reclama y espera de él, y su forma de actuar dentro y fuera del proceso debe contribuir a evitar el delito y cualquier otra infracción 0 manifestación que afecte el orden y las relaciones sociales.

Una de las formas de conseguirlo es que su actuación está enmarcada según los principios que rigen la profesión, ya que el profesional del derecho debe actuar con parámetros encaminados a promover y garantizar que la función jurisdiccional se cumpla correctamente, así como a velar por las normas y la ética profesional, facilitar sus servicios a todo aquel que lo necesite, y colaborar con los organismos judiciales para cumplir los fines de la justicia.

Bajo este contexto, deriva la importancia de profundizar en el estudio de los principios que guían y rigen su actuación como auxiliar de la justicia, lo que constituye un aporte a la lucha contra la corrupción.

\section{Principios universales}

\section{Obrar según ciencia y a conciencia}

Este principio le impone al profesional el deber de conocer la materia en la que se desempeña y de aplicarla conforme a esos conocimientos teniendo como base los principios morales y deontológicos. Por una parte, la ciencia se estudia y aprende y, por otra, la conciencia se forma, se educa, por tanto, se espera del individuo, en este caso del abogado, una actuación conforme a una ética que refleja un nivel de conocimientos sobre el derecho y una autorresponsabilidad en cada uno de sus actos.

Tanto la ciencia como la conciencia del abogado pueden facilitar la actuación correcta del juez, cumpliendo con la legalidad. Cuando los abogados actúan con conocimiento y apego a las normas jurídicas, de antemano se está imponiendo al juez la posibilidad de ser justo y legal. Si bien esta actuación no anula la posibilidad de que los jueces se equivoquen o intencionalmente actúen contrario a derecho, este error será susceptible de reparación o enmienda, 
porque de utilizarse los medios de impugnación requeridos, podrá verificarse que, por alguna razón, el juez inferior falló en contra de la ley.

\section{Probidad profesional u honestidad}

Un abogado que se comporta adecuadamente en sus relaciones sociales y humanas ya constituye en sí mismo un freno a la corrupción. Contrario es lo que representa un profesional en derecho que estimula, a través de diversos medios y vías, al soborno de los funcionarios, y va provocando el contagio en el ámbito judicial, desde pequeñas faltas hacia los graves hechos de corrupción.

Es por esta razón, que la honestidad del abogado es principio de su actuación al tiempo que es un mecanismo preventivo para evitar que el juez se corrompa. Su ejemplo positivo es un medio de contención para que jueces y empleados judiciales sean íntegros.

La honestidad, integridad y justicia están contemplados como tales dentro los principios internacionales de conducta para la profesión jurídica. "El abogado deberá mantener en todo momento los estándares más altos de honestidad, integridad y justicia hacia los clientes, los tribunales, colegas y todos aquellos con quienes el abogado entre en contacto profesional" (International Bar Association, 2011).

\section{Principio de independencia}

La independencia del abogado posee puntos coincidentes con la que le viene atribuida al juez, pues ella funciona como una garantía de que nadie tiene derecho a interferir o hacer injerencia en la actuación del abogado, salvo aquellas que respondan a los intereses de su cliente y dentro de los marcos de las peticiones legítimas de su usuario. No tiene el profesional en derecho el deber de modificar los fines propios de su profesión por sus vínculos de amistad, o presiones que provengan de personas externas al proceso en que ha sido contratado.

La independencia del abogado debe constituirse en un paradigma de actuación profesional, pues esa misma condición de independencia es atributo de la función del juez, de modo que se encuentra legal y penalmente prohibido para el letrado defensor, tratar de influenciar o modificar la conducta 0 decisión de los jueces, manipulando o trazando estrategias para que dicten resoluciones a su favor. 
Dentro de la buena reputación del abogado está el mantener una conducta que ofrezca certeza al usuario de su comportamiento ético y de que actúa alejado del ejercicio de cualquier influencia sobre autoridades, como policías, fiscales, jueces o peritos, y que no es capaz de usar a los políticos como intermediarios para conseguir los fines que se pretenden con el proceso.

Cuando el abogado necesite conocer sobre el curso o estado de un proceso no debe acudir directamente al juez a preguntarle, ni tampoco debe interrogar a los funcionarios o empleados judiciales que laboran con el juez en lugares y por medios no establecidos. El abogado conoce, que solicitar de ese modo información es incorrecto, pues existen mecanismos procesales para conocer y notificarse de los resultados de un proceso, sin tener que recurrir a intercambios extraprocesales sobre un asunto determinado.

Las conversaciones descontextualizadas, los almuerzos en común, las visitas familiares entre abogados y jueces donde se discute $\mathrm{o}$ debate un asunto que es del conocimiento del juez, deprimen la soberanía de la judicatura. Actuaciones de esta naturaleza afectan la propia independencia del abogado y la de los jueces sin contar con la falta de imparcialidad con que aquel habrá de decidir.

\section{Principio de libertad}

Un abogado puede tener razones para rechazar un asunto. Esto significa autodeterminación para decidir qué casos acepta y cuáles rechaza con motivo de particulares situaciones.

Al analizar o atender a una persona, el abogado puede decidir a su exclusiva responsabilidad si atiende o no el caso sometido a su consideración. En muchas oportunidades, el abogado conoce que el litigio que se propone ante él, no tiene ninguna posibilidad legal de terminar con éxito, y en tal sentido, debe darlo a conocer al consultante, pues al abogado le está autorizado no intervenir en el conflicto, y así informárselo al cliente.

El abogado también puede seguir el caso si es de interés de su cliente, previa comunicación de las pocas posibilidades de ganar el pleito. Eso también significa actuar con libertad y sobre todo con honestidad; lo que sí le está vedado al abogado es actuar consciente de que el caso no tiene posibilidades legales de éxito, pero intentaría ganarlo por medio del soborno o artimañas que conduzcan al error judicial. 
Según comenta Martínez Val (1981, p. 45), "la justicia es una virtud social, ya que, en cada hombre consciente, hay una idea primaria de lo que es justo, aun cuando esta idea sea vaga, simple y soterrada bajo vicios, pasiones e intereses".

La abogacía también debe perseguir la justicia, un valor muy superior incluso a la ley, pues cuando entran en conflicto la legalidad y la justicia misma, el profesional justo debe optar por ello y no por distorsionar el sentido de la justicia. La ley es un medio de realización de la justicia, pero cuando la primera no le sirve a la segunda por determinadas situaciones, como la falta de actualidad, o lo inusual del caso presentado, debe escogerse por la variante que más se avenga a lo justo.

Lo ideal sería que lo justo y lo legal coincidieran, pues las leyes deben responder al sentido de lo correcto y lo justamente necesario. El abogado posee las armas para demandar la aplicación de la justicia al caso concreto sin tener que acudir a subterfugios o hacer prevaricar a los que deben decidir:

Tu deber es luchar por el derecho, pero el día en que encuentres en conflicto el derecho con la justicia, lucha por la justicia. Pero la lucha por el derecho plantea, cada día, el problema del fin y los medios. El derecho no es un fin, sino un medio. En la escala de los valores no aparece el derecho. Aparece, en cambio, la justicia, que es un fin en sí y respecto de la cual el derecho es tan solo un medio de acceso. La lucha debe ser, pues, la lucha por la justicia. (Couture, 1974, p. 17)

Independientemente del conocimiento de leyes que posee el abogado, el sentido de la justicia no es algo que se pueda enseñar con los códigos, el sentido de lo justo y lo injusto conforma el saber común de la gente. Aunque la doctrina y la jurisprudencia se han dedicado a definir conceptualmente la justicia desde los tiempos remotos, el hombre común con un saber básico puede decidir qué es lo justo o aquello que no lo es, y el abogado, más que el resto de los ciudadanos, debe tener una noción clara de la justicia, y luchar por ella.

(Ossorio (2005, p. 23) hablaba de una "sensación de justicia que el abogado lleva dentro de sí, y que lo orienta al momento de estudiar un caso o evacuar una consulta más allá de su saber jurídico”. El hombre común conoce lo que es justo y pocas veces su pensamiento se aleja de lo que la ley prevé, pues la norma jurídica solo refleja la realidad y justeza que se desean. 
La libertad y la justicia son valores muy importantes que la sociedad reclama en sentido general, pero adquieren mayor relevancia para aquellos que intervienen en los procesos judiciales, porque solo es posible ser libre cuando se tiene cultura, conocimiento, y cuando la persona actúa con plena conciencia y dominio de lo que debe ser el resultado del buen profesional.

Con ese saber, el abogado podrá determinar si accede o no a las pretensiones de su cliente y, en caso de que se hayan comunicado suficientemente, también es libre para representarlo sobre la base de haberle informado sobre el fin que pueda resultar del caso.

\section{Principio de dignidad y decoro}

Este principio va dirigido a conservar la reputación profesional y personal del abogado. La dignidad se define como la actuación basada en el autorrespeto, calidad profesional e individual del abogado que pudiera definirlo como una persona de bien. La persona, que como atributo posee la dignidad, es capaz de respetarse a sí misma y a los demás, al tiempo que puede hacer valer su condición como profesional.

Este valor intenta proteger la lealtad y prohíbe el acaparamiento de clientes por medios ilícitos, fanfarroneo, simulaciones, utilización de declaraciones de testigos manipulados por él, o por haber ejercido presión o coacción sobre ellos. Todo ello indica un deterioro moral que termina degradando al abogado.

Además de ser digno como persona, debe mostrar respeto y consideración por su profesión, de modo que ese respeto exige que ni por sí mismo, ni por su cliente, ni por terceros debe el abogado dedicarse a ejercer influencias sobre las personas, ya sean testigos para que declaren lo que no ocurrió, o aportar documentos a sabiendas de que son falsos o usar ardides para modificar el sentido de la justicia.

El abogado obra como instrumento puesto al servicio de la justicia para lograr la paz social y el bien común. Si bien es cierto que la formación académica y la técnica jurídica son importantes, estas no deben ser incompatibles con la moral del abogado De Pina (1941 , p. 48) afirma que "un abogado sin moral desnaturaliza totalmente su profesión y se convierte en un arma nociva y peligrosa para la sociedad”. 
La labor de abogado enlaza con la garantía de justicia y ello implica que este profesional debe sentirse parte de ella, integrante digno y respetable de esa honorable y distinguida tarea del Estado. La abogacía forma parte de esa gran virtud que es la justicia. En ese dar o conceder a cada uno lo que le corresponde se encuentra el abogado.

\section{El principio de diligencia}

Ser diligente se refiere al cuidado, la capacidad técnica, el esmero, la constancia en la realización de los servicios profesionales que presta el abogado y su responsabilidad y deberes para con el cliente y con la sociedad en general. En este aspecto se tienen en cuenta el nivel de organización para trabajar y la disciplina que impone a sus subalternos en caso de que tenga auxiliares.

El abogado demuestra su diligencia a diario, incluye en ello la puntualidad a los actos públicos, que es fundamental, el cumplimiento de los horarios en que se cita con su cliente, la información constante y debida con este, el cumplimiento de los términos procesales, el dominio de las leyes, y las posibilidades de redactar escritos fundamentados y razonados. Son incontables los aspectos que muestran la diligencia del abogado.

Los abogados pondrán al servicio del cliente todo su saber y diligencia, actuando con celo es los asuntos a él encargados. Es deber del profesional en derecho dedicarse con esmero y puntualidad a los asuntos de su cliente y poner en su defensa todos los esfuerzos y conocimientos, y aun cuando tengan la necesidad de consultar con otros profesionales, la responsabilidad es suya con su cliente. Esta diligencia debida le evitará tener que utilizar otros mecanismos no legales para llegar al juez por medios ilegítimos.

El profesional del derecho debe tener en cuenta los límites del poder especial concedido para cumplir con el mandato que el cliente le ha encomendado. Aun cuando el abogado estime que existen otros aspectos que pueden dilucidarse o derivarse del proceso que se ventila, todas las decisiones de continuar y formular peticiones deben realizarse previa consulta y acuerdo con su cliente. De ahí el nivel de comunicación que se le exige con quien solicitó sus servicios.

Así como los clientes y órganos jurisdiccionales no deben hacerse cargo de los asuntos que le competen al abogado, este último debe asumir la responsabilidad en lo que le corresponde, lo que implica actuar como 
profesional y ser diligente con sus propios asuntos. Podría decirse que esto nace y se desarrolla con la persona y se extiende al ámbito profesional.

\section{Principio de desinterés}

El desinterés es también un elemento básico en la personalidad del abogado que actúa con transparencia y libertad, y ello incide positivamente en evitar la corrupción judicial, o al menos no se someterá el abogado a pedir más de lo que le corresponde por el recorrido legal.

Si el abogado actúa de forma libre, comprometido solo sobre la base de la ley con el cliente, si ha sido sincero con él y no ha pedido más de lo que le corresponde en justicia, no tiene por qué intentar acciones de soborno o entrega de dádivas para conseguir propósitos que no le corresponden.

Al abogado no ha de importarle en demasía el monto que ha de solicitar como retribución a su cliente, o al menos, no debe interesarle más por el dinero que por la razón que tiene su cliente para litigar; pues muchas veces tendrá que sacrificar sus propios intereses personales por cumplir con los deberes que le impone su profesión. Actuar desinteresadamente sin sobreestimar la clase social o condición económica del cliente sería una premisa fundamental para honrar su oficio.

\section{Principio de corrección}

La corrección significa actuar comedidamente conforme con los principios y reglas morales y jurídicas que guían esta honorable profesión. El uso de las buenas costumbres que han acompañado la actuación de los abogados en el desarrollo de la humanidad como paradigma no debe perderse en la etapa actual.

Los sentimientos de fraternidad, lealtad, consideración y respeto entre los colegas que conforman la comunidad de abogados, así como los demás juristas que lo rodean, entre los que se incluyen los jueces, permite que esta virtud basada en vivir y desempeñarse correctamente como profesional en sus relaciones humanas y especialmente con sus clientes, y con la sociedad, prestigie al abogado y evite que le haga perder la perspectiva de comportarse adecuadamente dentro de la sociedad $\mathrm{y}$, por tanto, se evitará el delito y cualquier comportamiento ilícito provocado por él. 
Dentro de las grandes virtudes que acompañan a la corrección se encuentran la seriedad. Al abogado se le exige ser discreto, reservado, cortés, honesto y actuar con rectitud. Son virtudes que deben acompañar a todos los seres humanos, pero en el caso del abogado, en particular, constituyen una exigencia ética y moral bien demandada por su profesión.

\section{Principio de información}

Es deber del abogado garantizar el flujo de información con su cliente con respecto al estado de su proceso y las posibilidades que ofrece la ley en relación con su caso. Este deber encierra la obligación del abogado de ponerse en contacto con los documentos y solicitar por los canales legales la información necesaria, no solo del proceso en sí, sino de las normas legales aplicables al caso y de ahí revisar muy escrupulosamente todos los detalles, de modo que pueda informar correctamente a su cliente y defender sus tesis ante el órgano jurisdiccional con conocimiento de causa.

El abogado debe notificarse a diario sobre el estado del proceso y poder responder las inquietudes de su cliente, para que aquel no se encuentre en la desesperación de acudir ante los empleados judiciales o jueces para interesarse por el asunto, generalmente la falta de ubicación del abogado o de información es lo que provoca que el cliente llegue a buscar información a través de los funcionarios y empleados judiciales, lo cual es un riesgo muy grande para la justicia, su transparencia y prestigio.

Por tanto, como lo expresa Martínez Val (1981), "es de vital importancia su análisis riguroso para no caer en hábitos mentales, entendidos como juicios emitidos sin previa comprobación fáctica de su validez" (p. 46). Puede acontecer que, por diferentes causas, el abogado no tenga una respuesta para ofrecerle al cliente y en tales casos se le ofrecen evasivas o respuestas con falta de objetividad, situación que representa irrespeto al cliente y a la justicia en general.

\section{Principio de reserva o secreto profesional}

Los abogados conocen que una de las características de sus funciones es que el cliente le hará saber una serie de informaciones relacionadas con el caso, de las cuales debe guardar secreto, es decir, entre ambos surge ambiente de confidencialidad derivada de la profesión. 
La Constitución de la República del Ecuador consagra el derecho a la reserva profesional. Así, el artículo 20 expresamente establece que

“el Estado garantizará la cláusula de conciencia a toda persona, y el secreto profesional y la reserva de la fuente a quienes informen, emitan sus opiniones a través de los medios u otras formas de comunicación, o laboren en cualquier actividad de comunicación. (Asamblea Nacional , 2008).

Cuando los abogados conocen los aspectos o circunstancias del asunto no deben propagar ni revelar las informaciones de su cliente, ni siquiera después de concluida la relación abogado-cliente. La jurisprudencia también hace gala del respeto a tal principio como se observa en la siguiente referencia:

El secreto profesional impone un deber especial de parte del Estado a efectos de preservar su eficaz cumplimiento. Dichas acciones de parte del Estado deben concretarse en una adecuada legislación, así como en la promoción de una cultura de respeto al ejercicio de las profesiones en general y, en especial, de aquellas que tienen directa implicación con la promoción de los derechos y libertades públicas, como es el caso de la abogacía y el ejercicio del derecho de defensa (...). (Jurisprudencia del Tribunal Constitucional Peruano, 2005)

Este es el principio general, pero como toda regla tiene sus excepciones, puede darse el caso de que las confidencias ofrecidas entren en colisión con los intereses legítimos de la sociedad, o simplemente, que signifiquen un perjuicio injustificado para terceros que no tienen culpa en el proceso. Significa que no se trata de guardar el secreto en contra de los derechos o intereses generales ni contra otra persona o personas que se encuentren injustamente el riesgo de que se afecten derechos fundamentales.

El Código de ética profesional de la Federación Mexicana de Colegios de Abogados regula los casos en los que el abogado debe revelar el secreto: "El secreto profesional podrá revelarse cuando de mantenerse se sigan: 1) daño grave para la sociedad; 2) daño grave para un inocente” (Federación Mexicana de Abogados, 2020).

En consonancia con lo anterior, se agrega:

También, la obligación del secreto profesional cede a las necesidades de defensa personal del abogado, cuando es objeto de persecuciones de su 
cliente. Puede revelar, entonces, lo que sea indispensable para su defensa y exhibir para el mismo objeto los documentos que aquel le haya confiado. Cuando un cliente comunicare a un abogado la intención de cometer un delito, tal confidencia no quedará amparada por el secreto profesional, y el abogado deberá hacer las revelaciones necesarias para prevenir un acto delictuoso o proteger a personas en peligro. (Federación Mexicana de Abogados, 2020)

El Código de ética profesional de Bolivia prevé, en su artículo 22, que en el supuesto de que un abogado sea acusado por su cliente, el profesional en derecho podrá revelar el secreto profesional en defensa de la verdad, aunque al hacerlo tenga que verse obligado a divulgar confidencias que el cliente le hubiera hecho en el pasado.

Cuando el cliente comunica a su abogado la intención de cometer un crimen 0 delito, esta confidencia no se encuentra protegida por el secreto profesional. El abogado está obligado a revelarlo con objeto de evitar la comisión de un crimen o delito protegiendo a quienes se encuentren en peligro (Consejo de Ministros, 2001). Cuando se corre el riesgo de dañar el bien común, la reputación, libertad o seguridad de otros o de afectar a terceros no responsables, la situación se torna polémica, pues se considera que no se justifica este comportamiento. El derecho de unos termina cuando se afectan los derechos de otras personas.

Si bien existe un derecho a guardar el secreto, ello no impide que ante posibles daños a los intereses generales o de perjuicios que pudieran derivarse contra terceros o contra el propio cliente o el abogado que escucha las confidencias, este último tenga que quedarse callado, mucho menos cuando ese acontecer puede provocar un delito de corrupción.

En ocasiones, los clientes o usuarios del abogado contactan con los jueces o empleados judiciales para facilitar a su favor la decisión, y suelen confesar a sus defensores lo que realizaron, y esa actitud puede convertir al abogado en cómplice o responsable de un hecho que termina siendo descubierto.

\section{Principio de lealtad procesal}

La lealtad en el orden procesal se conecta con muchas virtudes y principios de actuación que contribuyen y previenen la corrupción, pues el abogado no solo debe ser leal a su cliente, sino también a los jueces y a los colegas que integran el gremio. El abogado debe cumplir con la palabra empeñada, debe 
ser correcto, honesto y no traicionar la confianza a él ofrecida realizando un mal trabajo.

La lealtad significa fidelidad, responsabilidad, respeto, consideración, compromiso con la palabra ofrecida y con los principios generales que guían la actuación profesional.

Las relaciones humanas y el ejercicio profesional demandan del abogado un comportamiento digno de la profesión en que se ha formado, pues además de la conducta ética que a él se le exige, es un profesional y ello indica que se encuentra inmerso en unas exigencias que lo ponen al servicio de la sociedad.

El deber de lealtad procesal enseña que el abogado debe respetar la buena fe, los derechos de su contrario, respetar al juez y litigar con base en los principios de igualdad, y no valerse del engaño a su contrario o a los jueces para vencer en sus litigios. Eso es lo que se espera de un abogado honesto y correcto tanto en sus escritos de demanda y contestación, proposición de pruebas, alegaciones y e informes orales.

En el tema específico de la lealtad procesal se siguió en Colombia ante la jurisdicción disciplinaria un proceso en que fue ponente la jueza Julia Emma Garzón de Gómez. En la sentencia número 2012-01198 de 22 de abril de 2015, dictada en proceso por el Consejo Superior de la Judicatura, se fundamentó lo que los profesionales del derecho, antes de aceptar la designación como

apoderados judiciales, deben expresar a su cliente la verdadera opinión sobre la gestión confiada. Cuando un abogado omite su deber de proporcionar a su mandante una efectiva prestación del servicio profesional, se configura la falta prevista en el literal a) del Artículo 34 de la Ley 1123 del 2007, la cual es una de las faltas de lealtad con el cliente.

(Consejo Superior de la Judicatura, sentencia 2012-01198, 2015).

De una forma u otra, los Estados tienen reglamentado el régimen disciplinario para los profesionales que incurran en faltas o indisciplinas. Jueces, fiscales o abogados se encuentran sujetos a un comportamiento que está regido por normas y de vulnerarlas se verán inmersos en un proceso disciplinario. 


\section{Principio de colegialidad}

El tema de la colegialidad de los abogados se encuentra asociado a la necesidad de vinculación entre los miembros de una misma profesión. Con independencia de que los abogados ejerzan de forma independiente, estos están unidos debido a sus objetivos, fines que persiguen y la sociedad como escenario de servicio para lograr la aplicación correcta de la justicia.

Existe un vínculo orgánico y de solidaridad, que se establece entre los miembros de una misma profesión que los mantiene ligados por los mismos intereses que persiguen. Es así que, adoptar decisiones colegiadas sobre determinados aspectos que permitan elevar la calidad humana y profesional del abogado, es fundamental.

También, puede agregarse a ello que los abogados deben compartir las ideas de formación ética y profesional con la posibilidad de debatir y adoptar líneas de perfeccionamiento del prestigio del gremio de abogados, sobre todo porque son los abogados los que más se distancian de otros colegas dentro de los grupos de profesionales del derecho. Si bien no hay que obligar a los abogados a mantenerse unidos en su profesión, es muy factible y beneficioso que colegien determinados asuntos de interés común a ellos, pues eso da la idea de un vínculo interno.

Dentro de los tópicos que deben ser debatidos y colegiados de manera sistemática entre el gremio, se encuentran los riesgos que se corren por los letrados cuando se involucran en hechos de corrupción judicial y de cualquier tipo de actos que son nocivos a la sociedad y a sí mismos.

El prestigio de la abogacía depende de manera importante del comportamiento individual, por lo que debe ser propósito común defender la transparencia del cuerpo de abogados de cada país.

\section{El abogado como auxiliar de la justicia en la prevención de la corrupción}

El abogado como auxiliar de la justicia debe actuar bajo una serie de parámetros que han de guiar su conducta moral y ética, pues no solo es un servidor del cliente sino de la sociedad. Por ello, ha de asegurar la supervivencia social mediante la relación de lo jurídico y normativo. 
En ese deber de auxiliar de la impartición de justicia, no hay espacio legal para realizar maquinaciones fraudulentas encaminadas a obtener provecho de una causa, sino un procedimiento normativo y estratégico, para lograr que se aplique la justicia a los casos concretos cuando cuente con los elementos requeridos para presentar ante el órgano jurisdiccional competente sus peticiones.

Los procedimientos establecidos para cualquier materia o rama del derecho son viables para que los abogados puedan discurrir, por cada acto procesal, sin mayor dificultad. Ser auxiliar de la justicia, tiene una especial significación en la actividad jurisdiccional, sobre todo cuando se trata del abogado, pues este interviene desde el inicio del proceso hasta su finalización.

Le corresponde al abogado participar activamente en todas las fases del proceso, ofreciendo con cada diligencia, el impulso del mismo; si se está ante un asunto penal participará en la instrucción, en la proposición de pruebas, realizará sus alegaciones hasta obtener la sentencia que corresponde, y si es civil o de otra materia interviene en las demandas, contestaciones, proposiciones y práctica de pruebas y en cuanto acto procesal se requiera para la realización del proceso judicial.

Los profesionales del derecho, en su función de auxiliares de justicia, legitiman las decisiones de los jueces; en sus actuaciones fijan la naturaleza y alcance de las acciones judiciales, además de ser entes actores cuyos aportes sirven de sostén a las actividades que ellos realizan.

Por lo tanto, el abogado en su misión de auxiliar de la justicia debe velar que el flagelo de la corrupción no esté presente, porque la corrupción judicial es un fenómeno nocivo que distorsiona las normas legales, deteriora la actuación de los funcionarios públicos y destruye la propia imagen del abogado.

Cuando el abogado provoca la corrupción del juez por cualquiera de los medios ilegítimos que puede utilizar, no solo está vulnerando el orden normativo sino la justicia. En ese sentido, cuando se habla de corrupción no solo se trata de haber vulnerado la legalidad sino otros valores más trascendentes, como son la justicia, el prestigio de los funcionarios públicos, la ética de los abogados, el derecho legítimo de las personas a obtener un fallo justo, el derecho a la tutela judicial efectiva.

Por ello, el abogado debe exaltar la profesión que realiza,, su actuar y conducta debe caracterizarse por la rectitud, honestidad y sobre todo ética, 
y ello se garantiza con la equidad, honradez y buena fe. Los principios de actuación del abogado deben guiarlo hacia el respeto al Estado, la justicia, a su cliente y a la sociedad en general.

Este tema sobre los principios de actuación del abogado reflejan al profesional del derecho en su actuar diario no solo como el conocer e interpretar las leyes y la jurisprudencia, sino el obediencia de la ética para cumplir su loable misión que es lograr justicia.

\section{Conclusiones}

- La actuación correcta del abogado no solo exige un grado elevado de conocimiento, también es necesario que la comunidad pueda contar con un profesional del derecho con una sólida formación ética, honesto, probo y confiable.

- El abogado no solo está llamado a cumplir con las reglas éticas de la abogacía sino también con las normas exigibles al profesional del derecho y a todo profesional egresado de nivel superior. De ello se deriva su compromiso con el cliente, con la sociedad y con el bien común. Desde que la justicia pasó a constituirse en beneficio de la colectividad, el abogado dejó de ser exclusivo servidor de los intereses privados y pasó a ser un auxiliar de la justicia.

- El abogado defensor del cliente no es un ente ajeno a la justicia, no le está atribuida ninguna función que represente distorsionar la justicia, porque en tal caso no sería útil dentro de la sociedad. El engaño, las artimañas, la mala fe, los sobornos, las influencias o la falta de ética de un abogado son desvalores altamente reprochables y requieren ser atendidos por la comunidad de abogados con la debida rigurosidad.

- La corrupción judicial requiere de la profunda convicción de los ciudadanos para erradicarla, exige una lucha constante y sin cuartel a la que están llamados todos, para conseguir los dos fines que pueden hacerla realidad, el imperio de la ley y la igualdad ante ella.

- Los principios de actuación del abogado constituyen un conjunto de reglas esenciales que contribuyen a la prevención de la corrupción judicial en las sociedades modernas, por lo que las estrategias preventivas que pretendan implementarse en tal sentido deben contar con la activa participación de este grupo de profesionales que fungen como auxiliares de la justicia. 


\section{Referencias}

Brenes Córdova, A. (1913). Ensayo sobre la Moral y Profesión del Abogado. Revista del Colegio de Abogados,. 4-16. Recuperado de:http://ucsderecho.cimsa.cr/archivos/ EticaJuridica/ETICA.

Consejo de Ministros. (2001). Código de ética profesional para el ejercicio de abogacía. Ciudad: Editorial.

Consejo Superior de la Judicatura (2015, 22 de abril). Sentencia 2012-01198. Magistrado ponente Dra. Julia Emma Garzón de Gómez. Recuperado de: https://xperta.legis. co/visor/tempjurcol.

Constitución de la República del Ecuador. (2008). Artículo, fecha del mismo (país).

Couture, E. (1974). Instituciones jurídicas .Buenos Aires: Arte.

De Pina, R. ( 1941 ). Temas de derecho procesal. Ciudad de México: Ediciones .Jurídicas .

Federación Mexicana de Abogados. (2020). Código de ética profesional. Recuperado de: www.federacionmexabogados. org/etica.html

International Bar Association. (28 de mayo de 2011). Principios internacionales de conducta para la profesión jurídica. IBA. USA.Recuperado de:https://www.ibanet. org > Document

Jurisprudencia del Tribunal Constitucional Peruano (Tribunal Constitucional de Lima. Recuperado de: www.lozavalos.com.pe/alertainformativa/index de 11 de 2005).

Lega, C. (1983). Deontología de la profesión de abogado. Madrid: Editorial Civitas.

Martínez Val, J. M. (1981). Abogacía y abogado. Barcelona: Bosch, Casa Editorial S.A.

Monroy-Cabra, M. G. (2005). Ética del abogado. Bogotá: Ediciones Librería del Profesional.

Ochoa, A. M. (2015). ¿Qué intereses deben defenderse? Revista Internacional de Derecho y Literatura, vol. 1 nro. 2, 337-370. Recuperado de: https://scholar.google. com/citations

Ossorio, A. (2005). El alma de la toga. México: Editorial Porrúa.

Viñas, R. H. (1972 ). Ética de la abogacía y de la procuración. Deontología jurídica . Buenos Aires: Pannedile. 